\title{
Using Rubrics to Assess e-learning in Vocational Education
}

\author{
M. Muktiarni ${ }^{1, *}$, A. Ana ${ }^{1,}$, Lai Chee Sern" ${ }^{2}$, S. Saripudin ${ }^{3}$ \\ ${ }^{1}$ Fakultas Pendidikan Teknologi dan Kejuruan, Universitas Pendidikan Indonesia, Jl. Dr. Setiabudi No. 229 \\ Bandung, Indonesia \\ ${ }^{2}$ Fakulti Pendidikan Teknikal dan Vokasional, Universiti Tun Hussein Onn Malaysia, 86400 Parit Raja, Johor, Malaysia \\ ${ }^{3}$ Politeknik TEDC Bandung
}

1.muktiarni@upi.edu, ana@upi.edu

2Icsern@uthm.edu.my

3bangsarip@upi.edu, saripudin@poltektedc.ac.id

Abstract: A rubric is an assessment tool that explicitly articulates the specific components and expectations for an assignment by listing criteria. It is important to include clear as well as concise descriptions of each criterion and level of performance when writing a rubric. The criteria are also needed to align with the assignment objectives. This study aims to see the effectiveness of using a rubric in e-learning assessments in vocational education using descriptive research with a cross-sectional approach. We conducted a limited survey of lecturers regarding the effectiveness of using rubrics in e-learning. Lecturers who were the sample of this study decided using a purposive sample. In capturing data, we used a research instrument in the form of a questionnaire using a Likert scale. The research results showed that there are many benefits of rubrics for both instructors and students. Using rubrics establishes clear expectations for students, saves instructors time in grading, and aids in grading consistency among teaching assistants. Rubrics allow for quick and detailed feedback and provide data to refine teaching methods based on results. Rubrics also help students to understand the requirements and expectations better, focus on required elements, see how assignments align with learning objectives and improve their work based on the instructor's feedback.

Keywords: Assessment, E-learning, Rubrics, Vocational education.

\section{Corresponding Author}

${ }^{1}$ Fakultas Pendidikan Teknologi dan Kejuruan, Universitas Pendidikan Indonesia, Jl. Dr. Setiabudi No. 229 Bandung, Indonesia

*muktiarni@upi.edu

\section{Introduction}

Evaluating student achievement by examining the performance of students, either directly or indirectly, is necessary. The assessment reflects the type of activity or real-world skills that will be performed by the students in the future, after completion of the course and apply what they have taught (Baldwin and Trespalacios, 2017).

Type Rate in the learning process consists of two; onsite, and online (Chen and Jia, 2016). Onsite means the teacher can monitor the test carefully and directly observe the presentations, demonstrations, or communication. Onsite assessment and face-to-face-feedback have some advantages, especially when the feedback needs to be delivered with empathy and motivation (Darling et al., 2020). The second type of assessment is an online assessment where students' work can be sent and reviewed digitally. Meanwhile, students' performance can be recorded or broadcast live, knowledge can be assessed objectively through computer-based testing, and progress can be tracked over time through the log or blog (Benson and Brack, 2010).

Electronic learning (e-learning) is defined as the delivery of learning material via computer or telecommunications media such as the Internet, intranet, and an extranet, as well as digital media (Kumar and Belanger, 2018; Bentley et al., 2018; Nordseth et al., 2010). The rapid technological developments continue to make the education system (Seifert, 2017). The educational system continues to experience growth from only using the conventional system to switch to an all-digital system (Orlando, 2011; Muktiarni et al., 2019). Initially, the learning process only occurs in the classroom, but now the learning process is not limited by space and time. The current all-digital education system 
provides a method of learning which is known as blended learning and e-learning (Butcher and Wilson, 2013).

E-learning or the Electronic Learning method is a way of teaching and learning using electronic media and uses the Internet as an intermediary in the learning process (Begicevic et al., 2017), as shown in Figure 1.

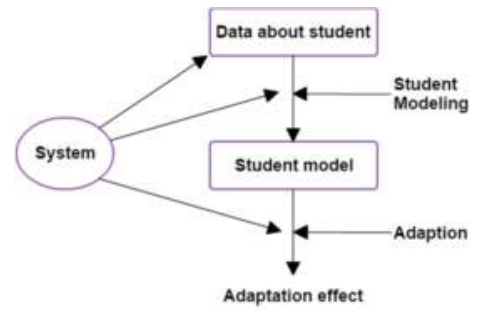

Fig. 1 The architecture of an adaptive e-learning system. Adapted from "From adaptive hypermedia to the adaptive web"

Characteristics of e-learning is a network, which enables the quick fixing, storing or retrieving distribution, and learning and information sharing.

Generally, evaluating the students' progress is essential to the educational process. Evaluation is not to only measure progress but also functions in formative capacity to enable electronic instructors to identify effective assessment strategies (Begicevic et al., 2017). In the e-learning environment, an objective test can be programmed to automatically record the value for students after completion (Wu et al., 2017). The objective of the exam can also be designed to provide immediate feedback as appropriate. This strategy helps reduce time assessment of e-instructors because educators spend time assessing and providing feedback to students (Dean et al., 2012). However, not all assessments can be programmed for assessment, automatic feedback, and objective examinations because it is not always the most appropriate assessment tool (Tienson, 2019).

One of the evaluation tools that can be used in assessing the students' e-learning process is performance assessment. The performance assessment is an assessment tool that requires the demonstration of the knowledge and skills of the students, which can be done either individually or collaboratively. Besides, performance assessments require students to demonstrate the application of knowledge in a particular context (Moskal, 2003). The performance assessment as an activity requires students to make a response, create products, and demonstrate (Muskin, 2015). In developing the assessment, the performance assessment guide or guidelines used is a rubric (Popham, 2009).

The sections will facilitate students in learning and selfassessment, peer assessment, and ratings conducted by teachers (Rivasy et al., 2014). Additionally, a rubric can familiarize students to have understanding conceptually and have a mastery of skills (Ragupathi and Lee, 2020). In recent years, several studies have been published focusing on the use of rubrics to assess student work (Campbell, 2005; Timmermn et al., 2011).

\section{Method}

This research is a descriptive study with a crosssectional approach. The survey is conducted on lecturers who teach at Universitas Pendidikan Indonesia, especially in vocational education who are implementing e-learning learning. Researchers conducted a limited survey of lecturers regarding the effectiveness of using rubrics in e-learning. Lecturers who are the sample of this study decided using a purposive sample. Data collection is obtained by distributing questionnaires to 20 lecturers. There are several stages conducted in this study. First the preparation of a questionnaire instrument used for data collection. The research instrument consists of comprehensive rubric indicators for assessment in e-learning systems including instructional design, learning assessment, and instructional resources for teaching and learning, technology design and assessment rubric. The questionnaire develops using the Likert scale survey method. The Likert scale survey method is used in descriptive research to obtain data from lecturers regarding the effectiveness of using rubrics in elearning assessments, with the approach of agreeing /disagreeing, satisfied/dissatisfied about attitudes, opinions, behavior, or characteristics of the study. The researchers collect data quantitatively which is distributed online using the Google Form, which is then analysed statistically to show the trend of the responses given by the target population about the phenomena being discussed. The data obtained from the questionnaire is presented in the form of tables and diagrams to determine the trends of lecturers regarding the effectiveness of using rubrics in e-learning assessments. The indicators for the instrument questionnaire are shown in Table 1.

Table 1 The Comprehensive Rubric

\begin{tabular}{|c|l|l|}
\hline No & Comprehensive Rubric & Indicator Comprehensive Rubric \\
\hline 1 & Instructional design & Structure of learning. \\
\cline { 3 - 3 } & & Learning aims and objectives \\
\cline { 3 - 3 } & & Learning outcomes \\
\cline { 3 - 3 } & & Instructional strategies and method \\
\hline 2 & Assessment of learning & Goals and objectives \\
\hline
\end{tabular}




\begin{tabular}{|c|c|c|}
\hline No & Comprehensive Rubric & Indicator Comprehensive Rubric \\
\hline & & Strategies \\
\hline & & Grading \\
\hline & & Feedback \\
\hline & & Management \\
\hline \multirow[t]{6}{*}{3} & \multirow{6}{*}{$\begin{array}{l}\text { Instructional resources } \\
\text { for teaching and } \\
\text { learning }\end{array}$} & Provision \\
\hline & & Application \\
\hline & & Entitlement \\
\hline & & Variety \\
\hline & & Openness \\
\hline & & Academic integrity \\
\hline \multirow[t]{8}{*}{4} & \multirow[t]{8}{*}{ Technology Design } & Support \\
\hline & & Centricity \\
\hline & & Openness \\
\hline & & Authentication \\
\hline & & Access \\
\hline & & Interface \\
\hline & & Investment \\
\hline & & Management \\
\hline \multirow[t]{2}{*}{5} & \multirow[t]{2}{*}{ Rubric } & Analytic \\
\hline & & Holistic \\
\hline
\end{tabular}

\section{Results and Discussions}

\subsection{Instructional design}

The results of research on instructional design analysis of the learning needs and the use of appropriate strategies and methods are shown in Figure 2.

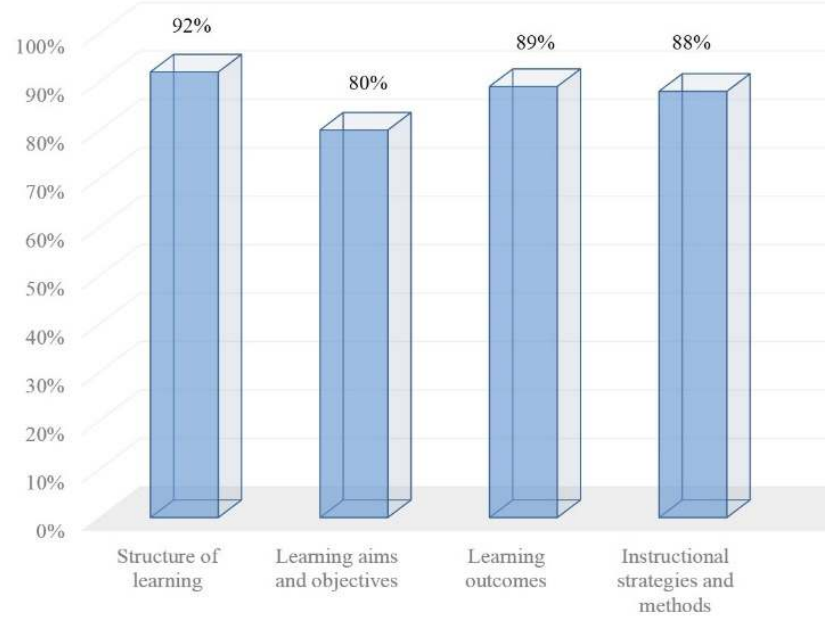

Fig. 2 Indicator Comprehensive Rubric for Instructional Design

According to lecturers, the instructional design required by the lecturer as a design and structure in the learning process is $92 \%$. $80 \%$ of the lecturer stated that the initial design in performing the learning process must be determined by learning objectives to achieve quality learning outcomes. $89 \%$ of lecturers stated that the determined learning outcomes must be following the design and can be achieved by students. $88 \%$ of lecturers stated learning strategies and methods are adjusted to the characteristics of online learning in vocational education. Instructional design is essential in designing learning media because the purpose of learning design in learning is to identify who the target of learning is and analyze the abilities, knowledge, and behavior of students. Specifically, in online learning, learning design affects the implementation of learning that is conducted online. This can affect the design of the assessment rubric used in the implementation of online learning (Khalil and Elkhider, 2016). Lecturers design a learning process that is tailored to the objectives of learning and the results that must be achieved by students, therefore to see the progress of the student's achievement of the competencies expected by the lecturer to develop a rubric that can continue to monitor.

\subsection{Assessment of learning}

The results in the assessment of online learning that is following the characteristics of learning can be seen in Figure 3.

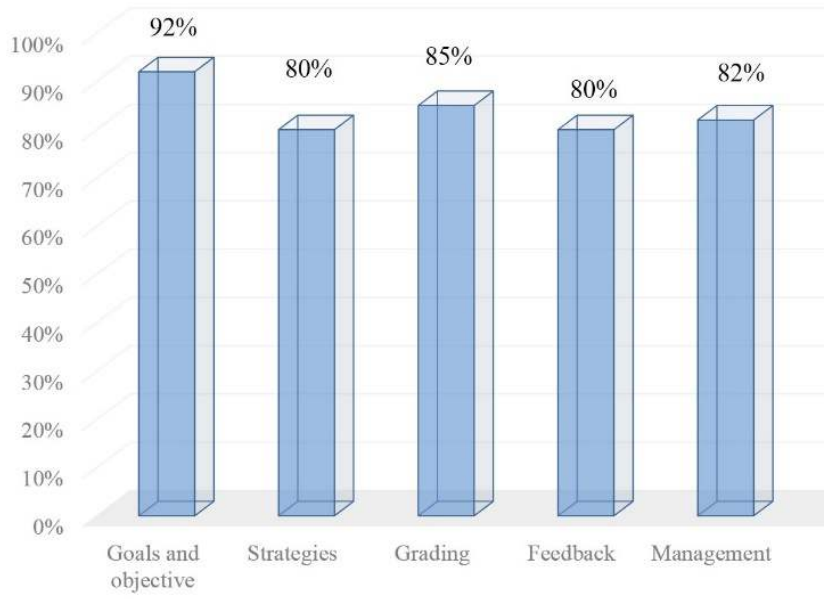

Fig. 3 Indicator Comprehensive Rubric for Assessment of learning

The learning process carried out online contains the basic objectives and the ultimate goal of the learning process, namely the achievement of overall student competence, therefore $92 \%$ of lecturers state that an educator 
must be able to describe goals and objectives in designing an assessment rubric, so students will know and able to follow the learning process for one semester. $80 \%$ of lecturers state that the assessment strategy in e-learning must be clear, welldefined, and measurable according to the level of the learners. $85 \%$ of lecturers stated that the rubric of e-learning assessment in vocational education must be following the characteristics of vocational education, the score is given fairly and transparently through an appropriate assessment instrument approved by the institution. $80 \%$ of lecturers said that the rubric developed by lecturers in vocational education for online learning must be able to provide feedback for both instructors and students and students are allowed to improve any competencies that have not been achieved. $82 \%$ of the lecturers stated that the rubric developed must be able to manage the online learning process in vocational education, management in this area should be able to accommodate all learning activities carried out for one semester.

Performance assessments an assessment that requires students to demonstrate performance and not to answer or choose answers from a variety of possible answers that are already available, such as the type of multiple-choice tests. Performance assessment has been widely believed to have a pedagogical value which is more and this can more accurately reflect student achievement than traditional multiple-choice tests (Fan and $\mathrm{Zu}, 2008$ ). Performance assessment is an assessment that emphasizes the aspects of skills shown by students and does not provide opportunities when students answer or choose answers from a series of possible answers that are already available (Wren, 2009). Performance assessment is an assessment that requires the demonstration of knowledge and skills of the students, which can be done either individually or as a group. Performance assessments require students to demonstrate the application of knowledge in a particular context (Moskal, 2003). Based on several definitions, it can be concluded that performance assessment is a form of assessment that requires students to demonstrate or apply all abilities, skills, and knowledge that have been acquired either in the form of performance or in the form of a product.

Performance assessment can be conducted using an instrument task and the rubric. The tasks may include individual and group assignments. Tasks are designed in such a way as to the subject of interest, so students can demonstrate the abilities or skills that are in the objectives of the assessment in the subject. The rubric is the assessment criteria used as guidelines in conducting a performance assessment or the work of learners. The use of the rubric will reduce subjectivity in assessing. The realization of the performance assessment includes: (1) group performance assessment, are tasks that must be done in groups, (2) individual performance assessment, which is an individual task that must be accomplished and performed independently, (3) portfolio (Guidy, 2009).

\subsection{Instructional resources for teaching and learning}

The results of research on instructional resources for teaching and learning are shown in Figure 4.

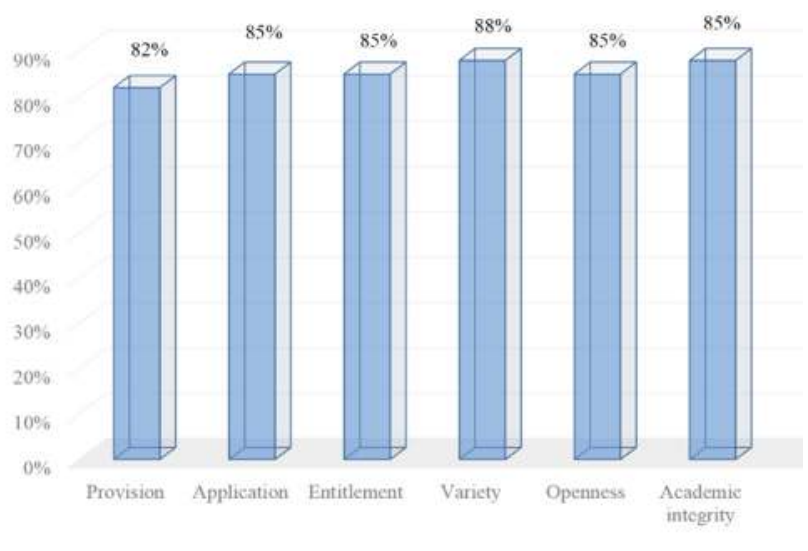

Fig. 4 Indicator Comprehensive Rubric for Instructional resources for teaching and learning

Instructional learning resources in the learning process provided by lecturers to students are fundamental as a framework in building student conceptual. $82 \%$ of the lecturers stated that the learning devices were designed according to the learning objectives so that students could integrate them into the learning process. $85 \%$ of lecturers feel that the development of applications/media in learning as a means of online learning, applications or media as a source of student learning in the online learning process can help increase student knowledge and interest in the online learning process. $85 \%$ of lecturers stated that learning resources can be accessed freely by students and students can search from various other limited sources, the online learning process gives freedom to both lecturers and students in finding and using various relevant sources. $88 \%$ of lecturers stated that learning resources varied from books, interactive multimedia, and other learning sources to meet different learning preferences for students. 85\% openness, instructors must provide opportunities for students to suggest their learning resources to be adopted in the online learning process. $88 \%$ academic integrity, in this case, the lecturer gives full encouragement to students in carrying out the learning process, bias anytime and anywhere because online learning is not limited by time and space. Learning resources are anything or resources that can be used for teaching and learning purposes to increase the efficiency and efficiency of learning objectives (Usman, 2016). 


\subsection{Technology Design}

The results of research on technology design for teaching and learning can be seen in Figure 5.

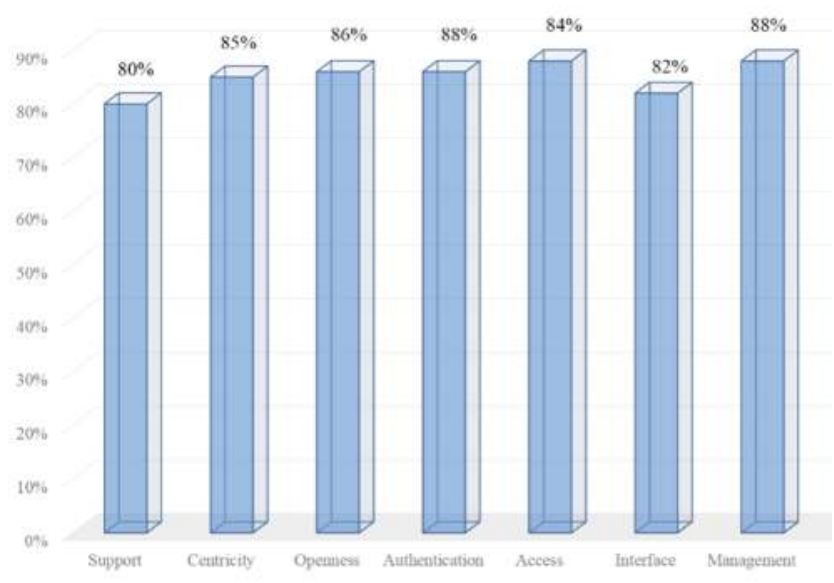

Fig. 5 Indicator Comprehensive Rubric for technology design

According to the lecturer, the need for supporting technology design for the teaching and learning process is $80 \%$, all technology and resources used to support the achievement of the aims and objectives of the lecturer in achieving learning outcomes for students. $85 \%$ of technology-centric design for teaching and learning, all technology and resources used to support a learner-centred approach to education rather than a lecturer-centred approach to education (Reigeluth, 2014). Learners must be in control and technology that can help them achieve learning outcomes. $86 \%$ of openness technology designs for teaching and learning, the technical infrastructure used to deliver teaching and learning is obtained and implemented by standards that maximize the achievement of learning objectives and various options to meet learning outcomes and academic needs of students (Paolini, 2015). 88\% of technology designs used with authentication for teaching and learning, authentication at multiple levels (learning devices, software, virtual learning environments, specific course/learning areas) must provide access to safe and secure teaching and learning environment with the minimum possible steps to access the study area. $84 \%$ access technology design for teaching and learning, virtual learning environment/learning area is device/platform agnostic that is used as much as possible so that it can be accessed through various software platforms, browsers, and computing devices. Instructors provide alternative sources if one of these tools cannot be accessed easily for technical reasons related to the special needs of students. $88 \%$ of interface technology design for teaching and learning, user interface and navigation in the learning area is quite simple so that it is conducive to the teaching and learning process without the need to have high-level ICT skills and competencies, simply everyone can access it easily. $82 \%$ user-friendly technology design, for teaching and learning. The technical requirements of instructional resources and virtual learning environments/learning spaces do not require students to make new adaptations to be able to access and use these resources to meet learning outcomes. $82 \%$ user-friendly technology design, for teaching and learning. The technical requirements of instructional resources and virtual learning environments/learning spaces do not require students to make new adaptations to be able to access and use these resources to meet learning outcomes.

\subsection{Rubric}

The results of the research on rubrics for e-learning assessment are shown in Figure 6. In practice, two rubrics can be used by lecturers, namely the holistic rubric and the analytic rubric. The results showed that $92 \%$ of lecturers used rubric analytics in the online learning process. The analytic rubric is a rubric that is commonly used to assess student performance. This rubric is used to grade assignments which can be divided into domains or criteria where each criterion can be assessed individually. Each criterion can be weighted according to its importance in achieving learning outcomes from the assignment. $8 \%$ of lecturers make a holistic rubric for e-learning assessment, a holistic rubric or a holistic rubric is used if there are difficulties or it is not possible to divide the assessment into separate criteria. This can occur because these criteria are interrelated and overlap one another. Such as complex creative tasks where students can approach it in various ways and the task cannot be done or difficult to divide into several components or assessment criteria. For this reason, a holistic student performance assessment is made. In a holistic class rubric, performance is articulated into a descriptive statement.

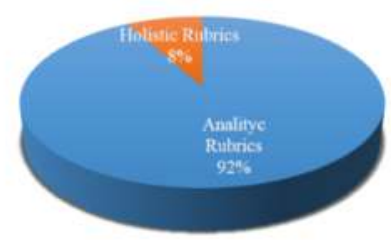

Fig. 6 Design rubrics for e-learning

A rubric is a scoring guide, which consists of the performance criteria previously set, which is used to evaluate the performance of students. One technique that can be used in evaluating student responses is through an assessment rubric (Moskal, 2003). The rubric is usually the form of 
special assessment instruments to assess and evaluate student performance or assess the resulting product as task completion performance (Mertler, 2000). A rubric-based assessment criteria guide which consists of measuring equipment (4 points, 6 points, or appropriate) and a description of the characteristics for each value of the score. The rubric describes the degree of quality, ability, or understanding along a circuit (Wiggins et al., 2005).

Rubrics and tasks in an assessment can be designed by the lecturer or can use a rubric that has been provided and created by the national government. One of the tasks is to utilize the resources of information technology. Educators can design assessment tasks and rubrics performance assessments of their own, or they may use or adapt tasks and rubrics created by the state education system or their district. The Internet is a source of performance assessment tasks and rubrics good assessment (Carole, 2003). Aspects assessed in the performance assessment there are five, namely: knowledge, reasoning, skills, products, Affect (attitude) (Stinggins, 1994). The realization of the performance assessment is primarily the task and the assessment criteria (rubrics).

The use of rubrics as assessment guidelines guarantees the accuracy of the instrument. The benefits of an assessment rubric are to give students a clear picture of what to expect before completing assessment activities (Moskal, 2003). There are two types of ways of scoring rubric for performance assessment is the analytical and holistic rubric. Performance analytic scoring rubric split into separate aspects and each aspect evaluated using a separate scale. Rubric holistic assessment using a single scale for evaluating the larger process. Aspects of the holistic scoring rubric, evaluated in combination (Moskal, 2003).

Before designing specific sections, one must decide whether to carry out a performance assessment or assessment products. Type any assessment to be carried out, first create the indicator. Decisions regarding the use of holistic or analytical approach to the assessment have several implications that may occur. Teachers should consider in advance how they will implement the results. If the overall score summative desired, a holistic assessment approach would be more desirable. Conversely, if the feedback is formative objectives, an analytic scoring rubric should be used.

The process of changing the value of the section into a value or category is more a process of logic. Educators must make the conversion system following the reporting system of assessment of student performance in terms of skills on campus. Criteria for scoring and predicate can be seen in Table 2.
Table 2 displays the criteria scoring and predicate. It can be seen that there are four scoring criteria: excellent (4), good (3), fair (2), and poor (1). The recommendations in designing an assessment rubric scoring include: (1) examine the suitability of the learning objectives with indicators of performance assessment to be carried out; (2) identify conformity with section indicators; (3) write thorough narrative descriptions for a good job and a bad job; explain the highest and lowest levels; (4) complete the rubric by describing the circuit level ranged from good jobs to the poor; (5) collect examples of student work as a portfolio; (6) revise the rubric, if necessary; and (7) discuss with experts on the effectiveness rubric and revision before the next execution (Wiggins et al., 2005).

Table 2 Criteria Scoring and Predicate

\begin{tabular}{|c|c|}
\hline $\begin{array}{l}\text { Excellent } \\
\text { (4) }\end{array}$ & $\begin{array}{l}\text { - Students display the performance assessment of } \\
\text { highly-skilled, consistent and continue to } \\
\text { improve its performance so that competence can } \\
\text { be achieved fully. } \\
\text { - Students displaying skillful performance } \\
\text { assessment, and showed an increase in } \\
\text { performance so that competence can be } \\
\text { controlled properly. }\end{array}$ \\
\hline Good & \\
\hline (3) & $\begin{array}{l}\text { - Students display the less skilled performance } \\
\text { assessment and show some inconsistency so that } \\
\text { a small fraction of competence that can be } \\
\text { achieved. }\end{array}$ \\
\hline $\begin{array}{l}\text { Fair } \\
\text { (2) }\end{array}$ & $\begin{array}{l}\text { performance assessment less-skilled students } \\
\text { from time to time or the performance of students } \\
\text { inconsistent that there are no signs of achieving } \\
\text { the expected competencies. }\end{array}$ \\
\hline $\begin{array}{l}\text { Poor } \\
\text { (1) }\end{array}$ & \\
\hline
\end{tabular}

The rubric is an alternative assessment tool that helps lecturers determine and explain what students must achieve and the performance criteria that have been determined in achieving competence. Students can monitor the progress of the competencies they have achieved, find out their weaknesses and how they can achieve the competencies (Raposo \& Martinez, 2011). The use of rubrics is important in the process of assessing student competencies and performance. A rubric can describe more specific characteristics of learning outcomes and the level of performance that must be achieved. Before tackling the task, they provide information about what standards must be met, 
how to assess performance, and after completing the task, they provide feedback (Garcia, et al., 2012).

Until now, we have seen the main contribution of using rubrics for both students and lecturers. The use of rubrics in multiple disciplines, and for a variety of purposes, such as to further develop student performance or to improve teaching and program assessment. It is that the perceptions of lecturers and students about rubrics are generally positive (Reddy \& Andrade, 2010).

\section{Conclusion}

Online technology provides the tools and models that facilitate and encourage the use of properly designed feedback system associates. Now more teachers and students joining the learning world are mixed, the future of education, the deployment of a peer-to-peer online system like the one discussed in this paper are likely to play an important role in the direction of post-secondary education, and there is evidence that this approach appears to increase the enthusiasm, learning, and enjoyment of students. The development of an assessment rubric carried out by lecturers in assessing the online learning process is one of the educational solutions and choices in evaluation because using a rubric sets a clear expectation for students, saves instructors time in assessing, and helps with assessment consistency. The assessment process is carried out not only on the products produced by students but starting from the initial process to the products produced. The results of this study can be a reference for system developers, programmers, operator's platform, teachers, and relevant personnel in education with the hope to perform an adaptive e-learning environment that is successful.

\section{Acknowledgements}

We would like to thank Fakultas Pendidikan Teknologi Kejuruan Universitas Pendidikan Indonesia. We also thank Lecturers of Program Studi Pendidikan Tata Boga for assisting this experiment.

\section{References}

Anstey, L. M., and Watson, G. L. P. (2018). Rubric for elearning tool evaluation. Retrieved October, 22, 2018.
Baldwin, S. J., and Trespalacios, J. (2017). Evaluation instruments and good practices in online education. Online Learning.

Begicevic, R.N., Balaban, I., Zugec, B., Klacmer Calopa, M., and Divjak, B. (2017). Framework for digitally mature schools. In EDEN 2017 Annual Conference Book of Abstracts (p. 39).

Benson, R., and Brack, C. (2010). Online learning and assessment in higher education: A planning guide. Elsevier.

Bentley, Y., Selassie, H., and Shegunshi, A. (2012). Design and Evaluation of Student-Focused e-learning. Electronic Journal of E-learning, 10(1), 1-12.

Butcher, N., and Wilson-Strydom, M. (2013). A guide to quality in online learning. 2013). Dallas, TX: Academic Partnerships. Retrieved on December, 12, 2013.

Campbell, A. (2005). Application of ICT and rubrics to the assessment process where professional judgement is involved: the features of an e-marking tool. Assessment and Evaluation in Higher Education, 30(5), 529-537.

Carole P. C, "Performance Assessment: Designing Appropriate Performance Tasks and Scoring Rubrics By." By. 12p,: In: Measuring Up: Assessment Issues for Teachers, Counselors, and Administrators: see 608. 0322003

Chen, W., and Jia, J. (2016). Comparison of online and onsite students' learning outcomes and experiences in a massively open online course in China. Journal of Educational Technology Development and Exchange (JETDE), 9(1), 5.

Darling-Hammond, L., Flook, L., Cook-Harvey, C., Barron, B., and Osher, D. (2020). Implications for educational practice of the science of learning and development. Applied Developmental Science, 24(2), 97-140.

Dean, C. B., and Hubbell, E. R. (2012). Classroom instruction that works: Research-based strategies for increasing student achievement. Ascd.

Fan, L., and Zhu, Y. (2008). Using performance assessment in secondary school mathematics: An empirical study in a Singapore classroom. Journal of Mathematics Education, 1(1), 132-152.

García-Ros, R., Pérez-González, F., Pérez-Blasco, J., \& Natividad, L. A. (2012). Evaluación del estrés académico en estudiantes de nueva incorporación a la universidad. Artículos en PDF disponibles desde 2007 hasta 2013. A partir de 2014 visítenos en www. elsevier. es/rlp, 44(2), 143154.

Guidy-Oulai, A. M. (2009). The development and application of a checklist for evaluating e-learning in organizations. 
Khalil, M. K., and Elkhider, I. A. (2016). Applying learning theories and instructional design models for effective instruction. Advances in physiology education, 40(2), 147156

Kumar Basak, S., Wotto, M., and Belanger, P. (2018). Elearning, M-learning and D-learning: Conceptual definition and comparative analysis. E-learning and Digital Media, 15(4), 191-216.

Mertler, C. A. (2000). Designing scoring rubrics for your classroom. Practical assessment, research, and evaluation, $7(1), 25$.

Moskal, B. M. (2003). Developing Classroom Performance Assessments and Scoring Rubrics-Part I. ERIC Digest.

Muktiarni, M., Widiaty, I., Abdullah, A. G., Ana, A., and Yulia, C. (2019, December). Digitalisation trend in education during industry 4.0. Journal of Physics: Conference Series, 1402(7), 077070.

Muskin, J. A. (2015). Student Learning Assessment and the Curriculum: Issues and Implications for Policy, Design and Implementation. In-Progress Reflections No. 1 on" Current and Critical Issues in the Curriculum and Learning". UNESCO International Bureau of Education

Nordseth, H., Ekker, S., and Munkvold, R. (2010, November). Tools for peer assessment in an e-learning environment. In Seminar. net (Vol. 6, No. 3).

Orlando, J. (2011). How to effectively assess online learning. Magna Publications.

Paolini, A. (2015). Enhancing teaching effectiveness and student learning outcomes. Journal of Effective Teaching, 15(1), 20-33

Popham, W. J. (2009). Assessment literacy for teachers: Faddish or fundamental?. Theory into practice, 48(1), 4-11.

Ragupathi, K., and Lee, A. (2020). Beyond fairness and consistency in grading: The Role of Rubrics in Higher Education. In Diversity and Inclusion in Global Higher Education (pp. 73-95). Palgrave Macmillan, Singapore

Raposo, M., \& Martínez, E. (2011). La rúbrica en la enseñanza universitaria: un recurso para la tutoría de grupos de estudiantes. Formación universitaria, 4(4), 19-28.

Reddy, Y. M., \& Andrade, H. (2010). A review of rubric use in higher education. Assessment \& evaluation in higher education, 35(4), 435-448.

Reigeluth, C. M. (2014). The learner-centered paradigm of education: Roles for technology. Educational Technology, $18-21$

Rivasy, M.R., De La Serna, M.C., and Martínez-Figueira, E. (2014). Electronic rubrics to assess competences in ICT subjects. European Education Research Journal, 13(5), 584594

Seifert, T. (2017). Training the teachers of tomorrow in an era of rapid technological advancement. i-Manager's Journal of Educational Technology, 14(1), 35

Stinggins Richard J, Student-Centered Classroom Assessment, New York: New York: Mac Millan College Publishing Company, 1994

Tienson-Tseng, H. L. (2019). Best Practices in Summative Assessment. In Biochemistry Education: From Theory to Practice (pp. 219-243). American Chemical Society

Timmerman, B. E. C., Strickland, D. C., Johnson, R. L., and Payne, J. R. (2011). Development of a 'universal' rubric for assessing undergraduates' scientific reasoning skills using scientific writing. Assessment and Evaluation in Higher Education, 36(5), 509-547.

Usman, Y. D. (2016). Educational resources: An integral component for effective school administration in Nigeria. Online Submission, 6(13), 27-37.

Valverde-Berrocoso, J., Garrido-Arroyo, M. D. C., BurgosVidela, C., and Morales-Cevallos, M. B. (2020). Trends in Educational Research about e-learning: A Systematic Literature Review (2009-2018). Sustainability, 12(12), 5153.

Wiggins, G. P., Wiggins, G., and McTighe, J. (2005). Understanding by design. Ascd.

Wiggins, G. P., Wiggins, G., and McTighe, J. (2005). Understanding by design. Ascd.

Wren, D. G. (2009). Performance assessment: a key component of a balanced assessment system. Research Brief. Report From The Department Of Reseacrh Evaluation, and Assessment, 2(2).

Wu, C. H., Chen, Y. S., and Chen, T. G. (2017). An adaptive e-learning system for enhancing learning performance: Based on dynamic scaffolding theory. Eurasia Journal of Mathematics, Science and Technology Education, 14(3), 903-913.

Jubaedah, Y., Rinekasari, N. R., Rohaeni, N., Maosul, A., a Ana, A. (2020). Competency based-assessment using electronic rubric: implementation on manual polishing practice in housekeeping. Journal of Engineering Science and Technology, 15(1), 046-053. 